\title{
Active ectopic thymus predicts poor outcome after thymectomy in class III myasthenia gravis
}

\author{
Vincenzo Ambrogi, MD, and Tommaso Claudio Mineo, MD
}

\begin{abstract}
Objective: The presence of ectopic thymic tissue has been considered one of the most significant predictors of poor outcome after thymectomy for myasthenia gravis, but the role of active ectopic tissue is unknown. The current study analyzed the importance of this factor on post-thymectomy outcome of patients with class III myasthenia gravis.
\end{abstract}

\begin{abstract}
Methods: We retrospectively reviewed 106 patients with class III, anti-acetylcholine receptor antibody-positive, nonthymomatous myasthenia gravis ( 70 female, 36 male; mean age, $41 \pm 17$ years) who underwent transsternal extended thymectomy between 1980 and 2005. Quality of life was assessed from 1996 with the Short Form 36 questionnaire. Prognosticators were investigated using complete stable remission and normalized component summaries as end points.

Results: Major morbidity rate was 5\% with no perioperative mortality. Ectopic thymic tissue was detected in 51 patients (48\%), 34 of whom (67\%) presented germinal centers. Complete follow-up was available in 96 patients (mean $160 \pm 91$ months). Fifty-two patients (54\%) achieved complete stable remission, and 20 patients (21\%) presented clinical and pharmacologic improvement. Lack of postoperative improvement in physical and psychosocial domains was significantly correlated with active ectopic thymus. At Kaplan-Meier evaluation, duration of symptoms ( $>12$ months $)(P=.04)$, oropharyngeal involvement $(P=.02)$, germinal centers $(P=.03)$, ectopic thymus $(P=.001)$, and active ectopic thymus $(P<.0001)$ were negative predictors of complete stable remission. The presence of active ectopic thymus was the most significant negative predictor of complete stable remission at Cox regression $(P=.03)$.
\end{abstract}

Conclusions: Extended thymectomy yields good outcome in patients with nonthymomatous class III myasthenia gravis. The presence of active ectopic thymus was the most significant predictor of poor outcome. These patients should be rigorously followed and undergo early aggressive therapy. (J Thorac Cardiovasc Surg 2012;143:601-6)

The removal of as much thymic tissue as possible is considered one of the key points for predicting complete stable remission (CSR) of nonthymomatous myasthenia gravis (MG) ${ }^{1-7}$ The persistence of ectopic thymic tissue ${ }^{8-11}$ is deemed as one of the main reasons of poor outcome after thymectomy. ${ }^{12,13}$ Furthermore, the presence of germinal centers in the thymus has reported to be a source of antibodies against acetylcholine receptors (anti-AchR Ab) and another significant negative prognostic factor. ${ }^{12,13}$

We hypothesized that the histologic evidence of active tissue in both native and ectopic thymus could predispose to the failure of a symptomatologic response to thymectomy. The purpose of our retrospective study was to analyze the most significant predictor of poor outcome after

\footnotetext{
From the Department of Thoracic Surgery, Multidisciplinary Myasthenia Gravis Unit, Tor Vergata University, Rome, Italy.

Disclosures: Authors have nothing to disclose with regard to commercial support. Received for publication Oct 14, 2010; revisions received April 11, 2011; accepted for publication April 26, 2011; available ahead of print Dec 19, 2011.

Address for reprints: Tommaso Claudio Mineo, MD, Cattedra di Chirurgia Toracica,

Policlinico Tor Vergata, Viale Oxford 81, 00133 Rome, Italy (E-mail: mineo@ med.uniroma2.it)

$0022-5223 / \$ 36.00$

Copyright (C) 2012 by The American Association for Thoracic Surgery

doi:10.1016/j.jtcvs.2011.04.050
}

thymectomy in class III nonthymomatous MG, with special attention to the presence of germinal centers in heterotopic thymus.

\section{PATIENTS AND METHODS \\ Patients}

Of a total of 194 myasthenic patients who underwent transsternal extended thymectomy at Tor Vergata University between 1980 and 2005, we retrospectively reviewed 106 patients affected with nonthymomatous, anti-AchR Ab-positive, class III MG (Figure 1). According to the Myasthenia Gravis Foundation of America (MGFA), class III was identified as a moderate weakness predominantly affecting limb or axial muscles (type a) or oropharyngeal muscles (type b). ${ }^{14}$ Patients operated before 2000 and therefore classified according to the Osserman's classification ${ }^{15}$ were retrospectively reclassified. We restricted the study only to this class because it is the most common and fittest to detect significant quality of life changes. We also excluded patients operated after 2005 to have a minimum follow-up of at least 5 years. Patient population consisted of 70 female and 36 male subjects aged 15 to 74 years (mean, $41.1 \pm 16.6$ years). Further demographic data are summarized in Table 1. Permission for activating the entire project, including the use of medical records and specimen reanalysis, was issued by the internal review board of Tor Vergata University. Each patient released written and fully informed consent to the use of personal data.

The diagnosis of MG was based on clinical features and 1 or more of the following criteria: response to edrophonium chloride, positive electromyography, and demonstration of circulating anti-AchR Ab. A quantitative MG score ${ }^{16}$ from 0 (no impairment) to 39 (maximum impairment) was also evaluated pre- and postoperatively. 


$\begin{array}{ll}\text { Abbreviations and Acronyms } \\ \text { anti-AchR } \mathrm{Ab}= & \text { antibodies against acetylcholine } \\ & \text { receptors } \\ \mathrm{CI} & \text { confidence interval } \\ \mathrm{CSR} & =\text { complete stable remission } \\ \mathrm{MCS} & =\text { mental component summary } \\ \text { MG } & =\text { myasthenia gravis } \\ \text { MGFA } & =\text { Myasthenia Gravis Foundation } \\ & \text { of America } \\ \text { PCS } & =\text { physical component summary } \\ \text { SF-36 } & =\text { Short Form } 36\end{array}$

Before thymectomy, all patients were receiving anticholinesterase drugs alone or in combination with steroids $(\mathrm{n}=28)$. Only 5 patients were also taking azathioprine. A medical panel composed of neurologists, thoracic surgeons, and anesthesiologists discussed the decision and timing for thymectomy. Each patient was clinically stable before surgery. In the presence of increasing weakness or bulbar symptoms, plasmapheresis $(n=17)$ or intravenous immunoglobulins $(\mathrm{n}=27)$ were administrated before surgery.

\section{Surgical Technique}

We consider thymectomy extended according to Sonnet and Jaretzki. ${ }^{17}$ The operation was accomplished under general anesthesia with single-lung ventilation. Only short-acting, nondepolarizing neuromuscular relaxants were occasionally used. During the operation and 12 hours after, oral pyridostigmine was administered through a nasogastric tube. Resection routinely included areas more frequently the site of ectopic thymic tissue ${ }^{2}$ such as perithymic fat tissue from anterior mediastinum, neck, aortocaval groove, aortopulmonary window, retroinnominate space, and both cardiophrenic angles.

At the end of the operation, we encouraged early extubation and physiotherapy. Pain control was preferably restricted to oral analgesics.

\section{Thymic Specimen Evaluation}

All excised tissue was routinely examined. Hematoxylin and eosinstained sections were prepared from paraffin-embedded blocks and examined under low magnification $(\times 20)$. Where histologic data were missing, the specimens were reprocessed by retrieving them from archive material.

Ectopic thymus was researched by randomly taking 1 from every $5 \mathrm{sec}-$ tions of fat tissue inclusion collected during thymectomy. The presence of the germinal centers was researched by examining visual fields of at least 5 sections of the thymus. Monoclonal antibodies against CD23 were used to demonstrate the presence of germinal centers. Briefly, sections from each specimen were cut at 3 to $5 \mu \mathrm{m}$, mounted on glass, and dried overnight at $37^{\circ} \mathrm{C}$. All sections were then deparaffinized in xylene, rehydrated through a graded alcohol series, and washed in phosphate-buffered saline. This buffer was used for all subsequent washes and for dilution of the antibodies. Tissue sections were heated twice in a microwave oven for 5 minutes each time at $700 \mathrm{~W}$ in citrate buffer $(\mathrm{pH} 6)$ and then processed with the standard streptavidin-biotin-immunoperoxidase method. Mouse monoclonal anti-human antibodies specific for CD23 (clone 1B12, Novocastra, UK) were used at a 1:100 dilution. All the primary antibodies were incubated for 1 hour at room temperature. Diaminobenzidine was used as the final chromogen, and hematoxylin was used as the nuclear counterstain. Negative controls for each tissue section were performed leaving out the primary antibody. Cytoplasmic staining with anti-human CD23 was scored as positive by an experienced pathologist.

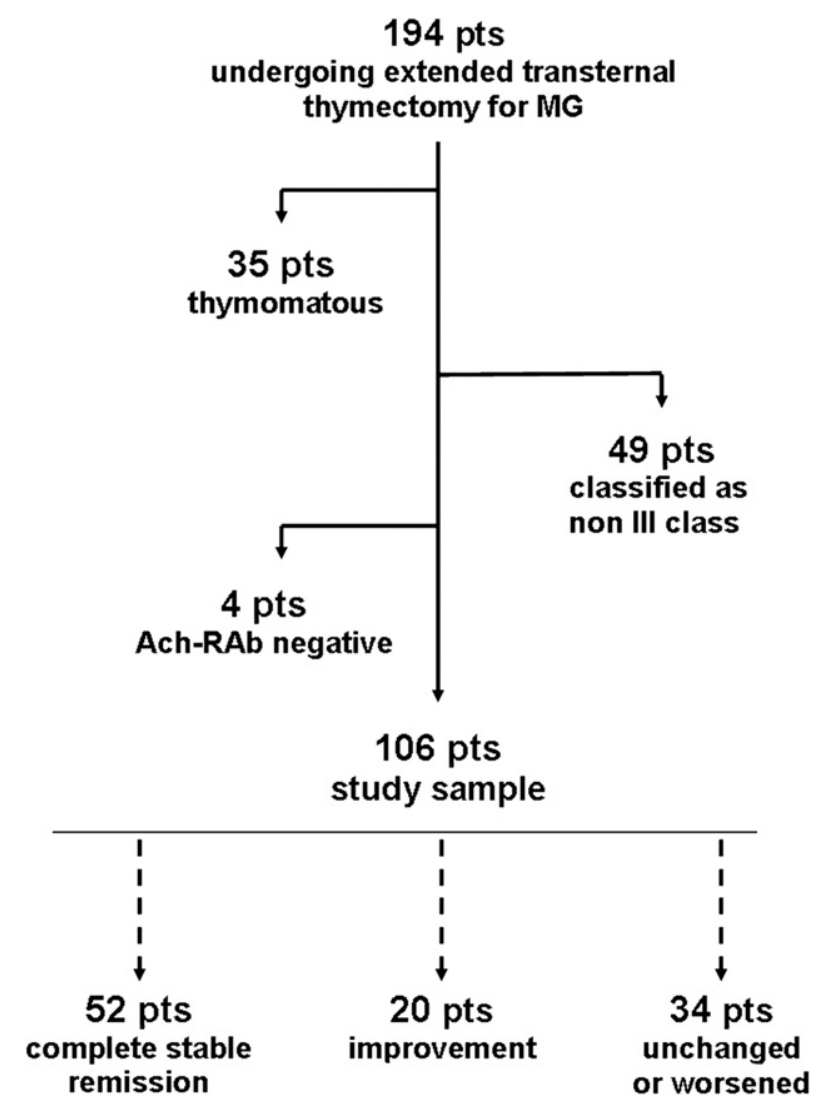

FIGURE 1. Diagram indicating patient's selection. Pts, Patients; $M G$, myasthenia gravis; Ach-RAb, acetylcholine receptor antibodies.

\section{Postoperative Evaluation}

Clinical outcome was always assessed according to the MGFA postintervention status classification ${ }^{14}$ during a multidisciplinary follow-up session. CSR was defined as no symptoms or sign of MG at careful examination for at least 1 year in the absence of therapy during that time. ${ }^{14}$

Since 1996, quality of life changes after surgery were measured by the Medical Outcomes Study Short Form 36 (SF-36) self-administered questionnaire. ${ }^{18}$ The SF-36 consists of 36 multiple-choice questions covering 8 health concepts: physical functioning, social functioning, physical role, emotional role, vitality, body pain, mental health, and general health perception (best score $=100$, worst $=0$ ). From these values, it is also possible to calculate a unique score for the physical component summary (PCS) and the mental component summary (MCS) (Health Assessment Laboratory, New England Medical Center, Boston, Mass, 1994). We repeated the same preoperative evaluations 6 months after thymectomy and then every 12 months after.

\section{Statistical Analysis}

We presented values of descriptive variables as mean \pm standard deviation. All analyses were performed with the Statistical Package for the Social Sciences (SPSS Inc, Chicago, Ill). The interdependence between prognostic factors and end points was tested by the 2-tailed chi-square test. End points were the improved postintervention status, normalized $(\geq 50)$ PCS values, and normalized $(\geq 50)$ MCS values. Significant variables were then analyzed with logistic regression. Correlations between continuous variables were analyzed by the Spearman test.

CSR survival was determined by the Kaplan-Meier method. Time to CSR was defined as the time between the day of surgery and the date of CSR. Patients who had not achieved CSR were censored with time to 
TABLE 1. Clinical features of patients undergoing thymectomy for class III myasthenia gravis

\begin{tabular}{|c|c|}
\hline Clinical features & Value \\
\hline Age $($ mean $\pm \mathrm{SD}$, y) & $41 \pm 17$ \\
\hline Early onset ( $\leq 40$ vs $>40$ y) & 72 vs 34 \\
\hline Sex (male vs female) & $36: 70$ \\
\hline Symptom duration (mean $\pm \mathrm{SD}$, mo) & $18 \pm 7$ \\
\hline Oropharyngeal symptoms (no. patients \%) & $29(27 \%)$ \\
\hline Preoperative MG score (0-39) (mean \pm SD) & $21 \pm 4$ \\
\hline Preoperative anti-AchR $\mathrm{Ab}($ mean $\pm \mathrm{SD}$ nmol/L) & $71 \pm 65^{*}$ \\
\hline Preoperative anticholinesterase dosage (mean \pm SD mg/d) & $201 \pm 80^{*}$ \\
\hline Preoperative steroids use (no. patients \%) & $27(25 \%)$ \\
\hline Hospital stay (mean $\pm \mathrm{SD}$, d) & $6.1 \pm 4.1$ \\
\hline Follow-up (mean $\pm \mathrm{SD}, \mathrm{mo}$ ) & $160 \pm 91$ \\
\hline 1 -y improvement + remission (no. patients $\%$ ) & $15(14 \%)$ \\
\hline $1-\mathrm{y}$ anti-AchR $\mathrm{Ab}($ mean $\pm \mathrm{SD}$ nmol/L) $\dagger$ & $15.5 \pm 5.2$ \\
\hline 1-y MGFA class (mean $\pm \mathrm{SD}$ ) & $1.9 \pm 1.0$ \\
\hline 1-y anticholinesterase dosage (mean $\pm \mathrm{SD} \mathrm{mg} / \mathrm{d}$ ) & $134 \pm 56$ \\
\hline 1-y MG score (0-39) (mean \pm SD) & $18 \pm 5$ \\
\hline Crude CSR rate (no. patients $\%$ )* & $52(54 \%)$ \\
\hline 5-y improvement + remission (no. patients $\%)^{*}$ & $51(53 \%)$ \\
\hline 5-y MGFA class $($ mean $\pm \mathrm{SD}) *$ & $1.4 \pm 0.8$ \\
\hline 5-y MG score $(0-39)(\text { mean } \pm S D)^{*}$ & $16 \pm 6$ \\
\hline 10 -y improvement + remission (no. patients $\%$ )* & $63(66 \%)$ \\
\hline 10-y MGFA class (mean $\pm \mathrm{SD})^{*}$ & $1.2 \pm 0.5$ \\
\hline 10-y MG score $(0-39)($ mean \pm SD)* & $14 \pm 8$ \\
\hline
\end{tabular}

$S D$, Standard deviation; $M G$, myasthenia gravisanti; anti-AchR $A b$, antibodies against acetylcholine receptors; MGFA, Myasthenia Gravis Foundation of America; CSR, complete stable remission. *Ninety-six patients who completed follow-up; 10 patients were lost. $†$ Fifty-one patients available.

CSR considered from operation to the most recent follow-up. Univariate analysis was performed by the log-rank test. Significant variables were subsequently analyzed by Cox regression.

\section{RESULTS}

\section{Operative Results}

The main clinical features are summarized in Table 1. There was no perioperative mortality, and the major morbidity rate was $5 \%$ with sternal wound infection $(\mathrm{n}=2)$, pneumonia and pleural effusion $(\mathrm{n}=2)$, and permanent phrenic nerve injury $(\mathrm{n}=1)$.

\section{Histologic Findings}

Histologic examination showed hyperplasia in 64 patients $(60 \%)$, normal thymus in 36 patients $(34 \%)$, and atrophic thymus in 6 patients $(6 \%)$. The presence of germinal centers was detected in 43 native thymuses (41\%): 26 (26/64, 41\%) with hyperplastic and $17(17 / 42,47 \%)$ with normal or atrophic histology. Heterotopic thymic tissue was found in 51 patients $(48 \%)$ and was more frequent in association with atrophic histology $(6 / 6,100 \%)$ than in the normal $(19 / 36,53 \%)$ or hyperplastic $(26 / 64,41 \%)$ native thymus. Location and frequencies are reported in Figure 2. Twenty-six patients had ectopic thymic tissue at 2 different sites, and 19 of those presented germinal centers in both foci. The presence of germinal centers in ectopic

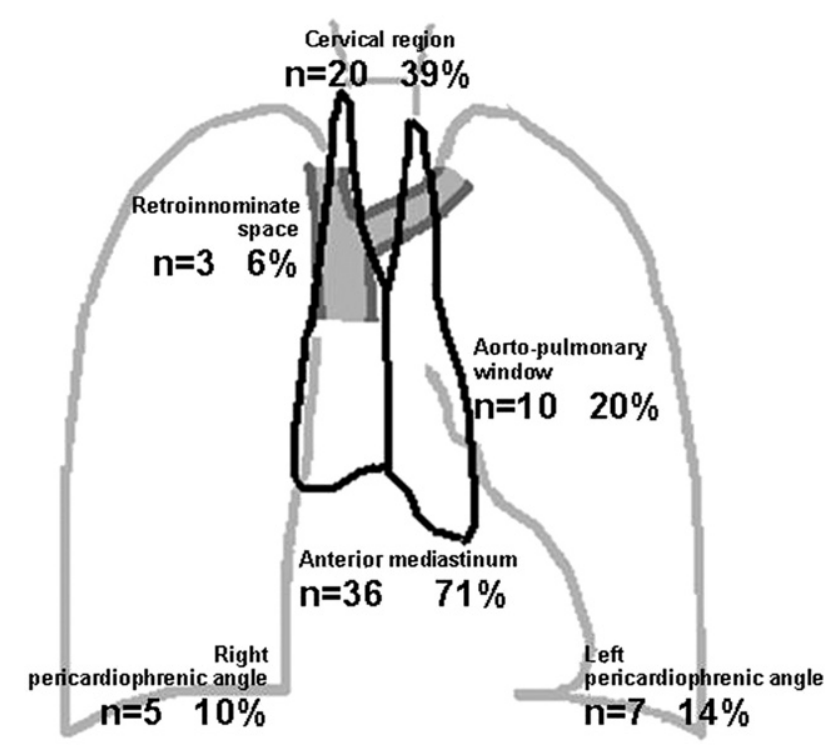

FIGURE 2. Distribution of ectopic thymic tissue and relative frequencies in a total population of 106 patients.

thymus was proved in 34 patients $(34 / 51,67 \%)$ and, namely, in all those with atrophic thymus.

\section{Long-Term Quality of Life Results}

Quality of life changes were available for 59 patients (Table 2). All domains except body pain significantly improved with time, up to a maximum of 10 years. At baseline, PCS values were more compromised in the presence of sole skeletal muscle involvement ( $40 \pm 12$ vs $50 \pm 12, P=.04$ ). On the other hand, MCS was significantly decreased ( $37 \pm$ 14 vs $51 \pm 11, P=.004)$ in patients with oropharyngeal symptoms. Postoperatively, there was a significant correlation of MG quantitative score with both PCS and MCS (Table 2).

SF-36 PCS and MCS stably achieved the end point value in approximately one quarter of the patients, and this rate continued to improve with time (Table 2). There was significant interdependence between the PCS $(P<.0001)$ or MCS $(P=.001)$ and the CSR. Both PCS and MCS normalization were significantly correlated with the absence of ectopic thymic tissue ( $P=.03$ and .01 , respectively), and PCS normalization was significantly correlated with the absence of active ectopic thymic tissue $(P=.0001)$ (Table 3$)$.

\section{Long-Term Complete Stable Remission Results}

Complete follow-up was available in 96 patients with a mean length of $160 \pm 91$ months (range 60-256 months). Five patients died, but only 2 of them died of causes directly related to MG.

Fifty-two patients (54\%) achieved CSR, and 20 patients (21\%) presented clinical and pharmacologic improvement. Quantitative MG score significantly improved at 5 years 
TABLE 2. Mean \pm standard deviation changes of Short Form 36 domains and relationship with symptoms

\begin{tabular}{|c|c|c|c|c|c|c|}
\hline SF-36 domains & Baseline & $1 y$ & $2 y$ & $3 y$ & $5 y$ & $10 \mathrm{y}$ \\
\hline No. patients & 59 & 56 & 48 & 41 & 32 & 13 \\
\hline Physical function $(0-100)$ & $55 \pm 12$ & $58 \pm 13$ & $60 \pm 10^{*}$ & $64 \pm 15 \dagger$ & $71 \pm 20 \ddagger$ & $68 \pm 17 \dagger$ \\
\hline Role physical (0-100) & $35 \pm 9$ & $38 \pm 12$ & $43 \pm 11^{*}$ & $49 \pm 10 \dagger$ & $54 \pm 21 \ddagger$ & $51 \pm 21 \dagger$ \\
\hline Body pain $(0-100)$ & $85 \pm 18$ & $67 \pm 19^{*}$ & $70 \pm 19$ & $74 \pm 15$ & $77 \pm 11$ & $73 \pm 10$ \\
\hline General health $(0-100)$ & $50 \pm 14$ & $54 \pm 14$ & $57 \pm 11^{*}$ & $59 \pm 10 \dagger$ & $63 \pm 15 \dagger$ & $60 \pm 18 \dagger$ \\
\hline Vitality $(0-100)$ & $47 \pm 10$ & $50 \pm 10$ & $52 \pm 10^{*}$ & $55 \pm 16^{*}$ & $58 \pm 9 \dagger$ & $56 \pm 13 \dagger$ \\
\hline Social function $(0-100)$ & $70 \pm 11$ & $71 \pm 11$ & $75 \pm 10^{*}$ & $78 \pm 12 \dagger$ & $81 \pm 14 \dagger$ & $75 \pm 10 \dagger$ \\
\hline Role emotional (0-100) & $46 \pm 12$ & $51 \pm 10^{*}$ & $58 \pm 9 \dagger$ & $66 \pm 11 \ddagger$ & $74 \pm 18 \ddagger$ & $76 \pm 22 \ddagger$ \\
\hline Mental health $(0-100)$ & $70 \pm 9$ & $72 \pm 11$ & $73 \pm 9$ & $74 \pm 8^{*}$ & $74 \pm 10^{*}$ & $74 \pm 19 *$ \\
\hline PCS $(0-70)$ & $43 \pm 9$ & $44 \pm 9$ & $45 \pm 8^{*}$ & $47 \pm 10^{*}$ & $48 \pm 7^{*}$ & $47 \pm 9^{*}$ \\
\hline $\operatorname{MCS}(0-70)$ & $47 \pm 7$ & $48 \pm 14$ & $49 \pm 10$ & $50 \pm 17^{*}$ & $50 \pm 13^{*}$ & $50 \pm 10^{*}$ \\
\hline PCS $\geq 50$ (no. patients \%) & $13(22 \%)$ & $14(25 \%)$ & $14(29 \%)$ & $14(34 \%)$ & $14(43 \%)$ & $8(61 \%)$ \\
\hline MCS $\geq 50$ (no. patients $\%$ ) & $16(28 \%)$ & $17(30 \%)$ & $17(35 \%)$ & $16(39 \%)$ & $16(50 \%)$ & $8(61 \%)$ \\
\hline Quantitative MG score (0-39) & $21 \pm 4$ & $18 \pm 5$ & $18 \pm 4$ & $17 \pm 4$ & $16 \pm 6^{*}$ & $14 \pm 8 \dagger$ \\
\hline Spearman PCS vs MG score (rho) & $-0.30^{*}$ & $-0.39 *$ & $-0.45 \dagger$ & $-0.48 \dagger$ & $-0.48 \dagger$ & $-0.56 \dagger$ \\
\hline Spearman MCS vs MG score (rho) & -0.16 & -0.21 & $-0.28 *$ & $-0.33^{*}$ & $-0.39 *$ & $-0.50 \dagger$ \\
\hline
\end{tabular}

(Table 2). Univariate analysis of factors influencing response to thymectomy is summarized in Table 3 .

The global improvement rate according to the symptomatic-medication response increased from $14 \%$ at 1 year to $53 \%$ at 5 years and $66 \%$ at 10 years, respectively (Table 1). CSR survival was $21 \%$ and $47 \%$ at 5 and 10 years, respectively. The median time from thymectomy to CSR was 88 months, ranging from 11 to 154 months. There was no significant association between CSR rate at 24 months and sex $(P=.36)$, age ( $<40$ vs $\geq 40$ years $)(P=.42)$, preoperative use of corticosteroids $(P=.07)$, preoperative histology (hyperplastic vs normal-atrophic) $(P=.07)$ or plasmapheresis $(P=.11)$, and need of postoperative intubation $(P=.33)$. On the other hand, shorter duration of disease $(<12$ months $)(P=.04)$, oropharyngeal involvement $(P=.02)$, presence of germinal centers in native or ectopic thymus $(P=.03)$, and presence of ectopic thymus $(P=.001)$ (Figure 3) were negative predictors. The presence of

TABLE 3. Univariate analysis of factors influencing response to thymectomy (chi-square test)

\begin{tabular}{|c|c|c|c|c|c|c|c|c|c|}
\hline & \multicolumn{2}{|c|}{ Postintervention status } & \multirow[b]{2}{*}{$P$ value } & \multicolumn{2}{|c|}{ PCS } & \multirow[b]{2}{*}{$P$ value } & \multicolumn{2}{|c|}{ MCS } & \multirow[b]{2}{*}{$P$ value } \\
\hline & Improved & Unchanged or worsened & & $\geq \mathbf{5 0}$ & $<\mathbf{5 0}$ & & $\geq \mathbf{5 0}$ & $<\mathbf{5 0}$ & \\
\hline \multicolumn{10}{|l|}{ Sex } \\
\hline Male & 19 & 11 & .08 & 4 & 12 & .65 & 7 & 9 & .27 \\
\hline Female & 53 & 13 & & 10 & 22 & & 9 & 23 & \\
\hline \multicolumn{10}{|c|}{ Symptom duration } \\
\hline$<12$ mo & 15 & 10 & .04 & 4 & 17 & .17 & 5 & 16 & .21 \\
\hline$\geq 12 \mathrm{mo}$ & 57 & 14 & & 10 & 17 & & 11 & 16 & \\
\hline \multicolumn{10}{|c|}{ Oropharyngeal involvement } \\
\hline Yes & 15 & 11 & .01 & 4 & 12 & .65 & 3 & 10 & .14 \\
\hline No & 57 & 13 & & 10 & 22 & & 13 & 22 & \\
\hline \multicolumn{10}{|l|}{ Histology } \\
\hline Hyperplasia & 57 & 4 & .06 & 10 & 21 & .60 & 13 & 18 & .19 \\
\hline Normal & 15 & 14 & & 4 & 11 & & 3 & 12 & \\
\hline Involuted & - & 6 & & 0 & 2 & & 0 & 2 & \\
\hline \multicolumn{10}{|c|}{ Germinal centers } \\
\hline No & 46 & 9 & .02 & 4 & 15 & .31 & 5 & 14 & .40 \\
\hline Yes & 26 & 15 & & 10 & 19 & & 11 & 18 & \\
\hline \multicolumn{10}{|c|}{ Ectopic thymic tissue } \\
\hline No & 41 & 6 & .01 & 3 & 19 & .03 & 3 & 19 & .01 \\
\hline Yes & 31 & 18 & & 11 & 15 & & 13 & 13 & \\
\hline \multicolumn{10}{|c|}{ Ectopic active tissue } \\
\hline No & 16 & 1 & .001 & 2 & 14 & .0001 & 5 & 10 & .05 \\
\hline Yes & 15 & 17 & & 9 & 1 & & 8 & 3 & \\
\hline
\end{tabular}

PCS, Physical component summary; MCS, mental component summary. 

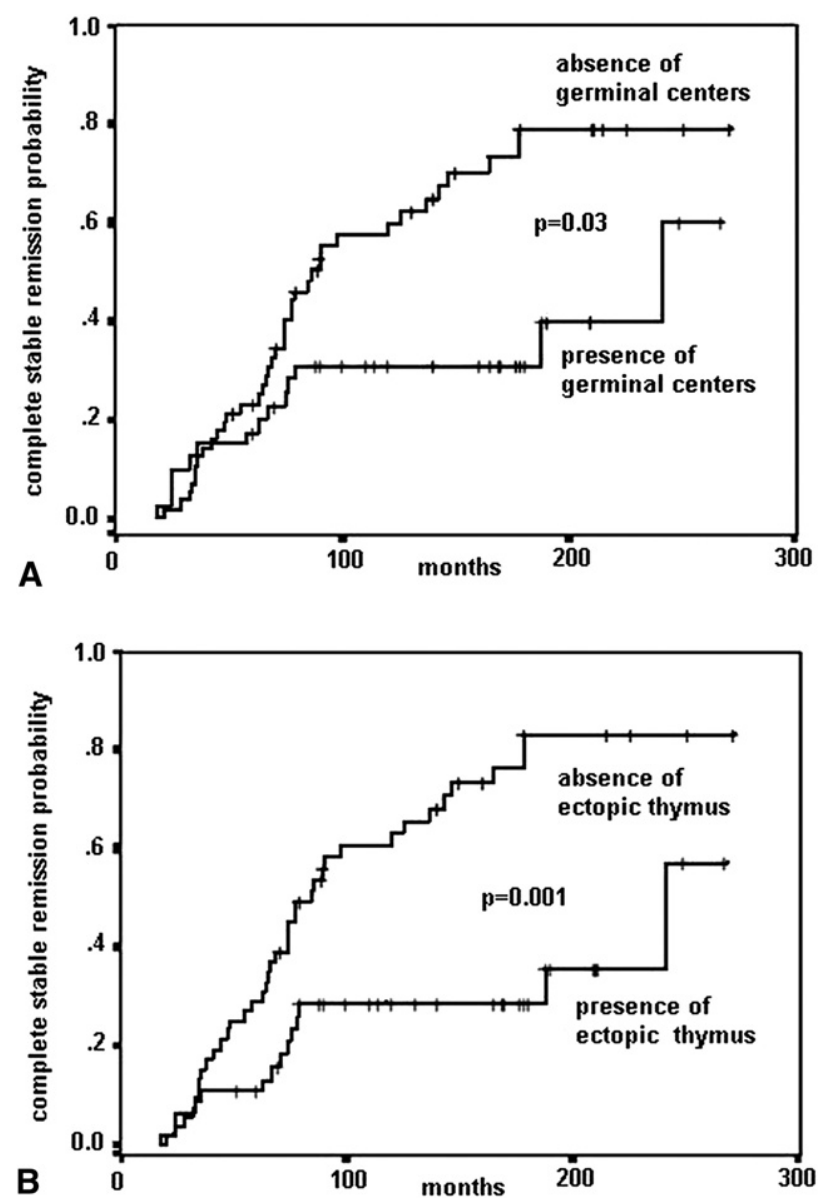

FIGURE 3. Cumulative complete remission Kaplan-Meier curve for the presence of ectopic thymic tissue (A) and germinal centers (B).

germinal centers in the ectopic thymus was a strong predictor of lack of CSR $(P>.0001)$.

\section{Multivariate Analysis}

At logistic regression, all end points were significantly influenced by the presence of ectopic thymic tissue: CSR $\exp \mathrm{B}=5.8(95 \%$ confidence interval $[\mathrm{CI}], 1.7-19.8$; $P=.005)$, PCS $\exp \mathrm{B}=4.6(95 \%$ CI, 1.1-19.7; $P=.03)$, MCS exp B $=6.3$ (95\% CI, 1.5-26.7; $P=.01)$. At Cox regression analysis, the presence of active ectopic thymic tissue $(P=.03$; odds ratio, $0.9 ; 95 \% \mathrm{CI}, 0.1-1.7)$ was selected as the most significant negative CSR prognosticator.

\section{COMMENT}

Thymectomy is considered an integrated step in the treatment of anti-Ach- $\mathrm{R} \mathrm{Ab-positive} \mathrm{MG.,3} \mathrm{The} \mathrm{site} \mathrm{of} \mathrm{anti-}$ AchR Ab production is likely located in the activated areas (ie, B-cell follicles and germinal centers) of thymic tissue. $^{12,13,19,20}$ Thus, the removal of as much thymic tissue as possible is considered the mainstay for a successful thymectomy. ${ }^{5,21}$

However, thymic tissue can also be present in heterotopic adjacent islets, ${ }^{8-11}$ and their persistence is considered one of the main reasons of scant symptomatic improvement after thymectomy. ${ }^{12,13}$ Our series claimed some interesting points concerning the prognostic role of ectopic thymic tissue.

First, the presence of ectopic tissue is a relatively frequent finding during thymic surgery. ${ }^{8-11}$ We evidenced ectopic thymic tissue in approximately half of the patients; it was found anywhere in the anterior mediastinum, in the lower cervical area, and even in the middle mediastinum (Figure 2). Therefore, routine and complete removal of these compartments is deemed necessary to maximize outcome as proposed by Jaretzki and Wolff. ${ }^{5}$

Second, despite the intention to achieve an extended surgical resection, we showed that the probability of leaving further residual foci is high. We postulate that the presence of heterotopic thymus is evidence of diffuse thymic spread in the thoracic-cervical regions. The possibility of a complete thymectomy seems to be a "chimera." However, in these instances, extended thymectomy might be performed for prognostic purposes or with a cytoreductive intent aimed at decreasing the antibody burden.

Third, we found that the presence of ectopic and mainly active tissue is more frequent in the case of an atrophic or normal thymus. This finding could justify the onset of anti-AchR Ab-positive MG even in patients with involuted and apparently "silent" thymus. ${ }^{22}$

Finally, we demonstrated that the discovery of ectopic thymus was the most significant predictor of poor response at multivariate analysis. This effect was enhanced by the presence of germinal centers. The poor response included both CSR and physical and psychosocial quality of life domains. Patients who present these features at histologic examination should be included in a different clinical pathway with stricter follow-up and a more aggressive therapeutic regimen based on immunosuppressive drugs, eventually leading to a reoperation.

The thymic germinal center is where B-lymphocytes differentiate to produce antibodies with high affinity toward antigens. Several studies hypothesized the production of anti-AchR Ab from the thymus, suggesting a critical role of the thymic germinal centers in the pathogenesis of $\mathrm{MG}^{4,13,19}$ The correlation between the presence of germinal centers, especially if located in ectopic tissue, and the poor outcome of thymectomy reinforces this hypothesis. ${ }^{12}$

We also observed that extended thymectomy may have a significant impact on quality of life. Nonthymomatous thymectomy can achieve significant improvement in both physical and psychosocial domains, which are particularly altered in MGFA class III. This positive effect can progressively increase over time. Previous studies concerning quality of life 
indifferently included thymomatous and nonthymomatous cause. $^{3,23}$ The lack of this discrimination may have some relevance in the evaluation of quality of life parameters, because thymomatous forms may have a more severe impairment because of adjuvant antineoplastic therapies and stricter controls. For these reasons, a comparison with previous studies may be unfair.

\section{Study Limitations}

Several limitations of this study deserve mention. The major limitation is represented by its retrospective nature. Another limitation is represented by the wide time span required to gather a consistent sample size, which implies obvious differences in diagnostic and therapeutic strategies due to scientific and technologic advancements. Finally, data on quality of life are available for only one half of the study population. Despite these limitations, the study provides valuable data based on a long-experienced single surgeon always performing an intentional extended thymectomy.

\section{CONCLUSIONS}

Extended thymectomy, when properly performed for both timing and extension, yields a satisfactory long-term outcome and quality of life in patients with nonthymomatous, anti-AchR Ab-positive, class III MG. Thymectomy is a mandatory step in a more accurate determination of the prognosis of the disease. The presence of active ectopic thymic tissue seems to be the most significant predictor of poor response to thymectomy. This finding should be useful to address these patients to a more rigorous follow-up and aggressive therapeutic regimen.

The authors thank Alfonso Baldi for the contribution in reassessing the specimens and all the staff members of the Myasthenia Gravis Unit of the Tor Vergata University, including neurologists, anesthesiologists, intensivists, psychologists, physiotherapists, and nurses, for professionalism and efforts during the last 25 years.

\section{References}

1. Blalock A, Harvery AM, Ford FF, Lilienthal J Jr. The treatment of myasthenia gravis by removal of the thymus gland. JAMA. 1941;117:1529-33.

2. Masaoka A, Yamakawa Y, Niwa H, Fukai I, Kondo S, Kobayashi M, et al. Extended thymectomy for myasthenia gravis patients-a 20-year review. Ann Thorac Surg. 1996;62:853-9.
3. Busch C, Machens A, Pichlmeier U, Emskötter T, Izbicki JR. Longterm outcome and quality of life after thymectomy for myasthenia gravis. Ann Surg. 1996;224: 225-32.

4. Okumura M, Ohta M, Takeuchi Y, Shiono H, Inoue M, Fukuhara K, et al. The immunologic role of thymectomy in the treatment of myasthenia gravis: implication of thymus-associated B-lymphocyte subset in reduction of the antiacetylcholine receptor antibody titer. J Thorac Cardiovasc Surg. 2003;126: 1922-8.

5. Jaretzki A III, Wolff M. "Maximal” thymectomy for myasthenia gravis. Surgical anatomy and operative technique. J Thorac Cardiovasc Surg. 1988;96:711-6.

6. Jaretzki A III, Penn AS, Younger DS, Wolff M, Olarte MR, Lovelace RE, et al. "Maximal" thymectomy for myasthenia gravis. Results. J Thorac Cardiovasc Surg. 1988;95:747-57.

7. Watanabe A, Watanabe T, Obama T, Mawatari T, Ohsawa H, Ichimiya Y, et al. Prognostic factors for myasthenic crisis after transsternal thymectomy in patients with myasthenia gravis. J Thorac Cardiovasc Surg. 2004;127:868-76.

8. Masaoka A, Nagakoa Y, Kotabe Y. Distribution of thymic tissue at the anterior mediastinum-current procedure in thymectomy. J Thorac Cardiovasc Surg. 1975;70:747-54.

9. Fukai I, Funato Y, Mizuno T, Hashimoto T, Masaoka A. Distribution of thymic tissue in the mediastinal adipose tissue. J Thorac Cardiovasc Surg. 1991;101: 1099-102.

10. Ashour M. Prevalence of ectopic thymic tissue in myasthenia gravis and its clinical significance. J Thorac Cardiovasc Surg. 1995;109:632-5.

11. Mineo TC, Pompeo E, Ambrogi V, Bernardi G, Sabato AF, Iani C. Video-assisted completion thymectomy in refractory myasthenia gravis. J Thorac Cardiovasc Surg. 1998;115:252-4.

12. Mori T, Nomori H, Ikeda K, Kobayashi H, Iwatani K, Kobayashi T. The distribution of parenchyma, follicles, and lymphocyte subsets in thymus of patients with myasthenia gravis, with special reference to remission after thymectomy. J Thorac Cardiovasc Surg. 2007;133:364-8.

13. Roxanis I, Micklem K, McConville J, Newsom-Davis J, Willcox N. Thymic myoid cells and germinal center formation in myasthenia gravis; possible roles in pathogenesis. J Neuroimmunol. 2002;125:185-97.

14. Jaretzki A III, Barohn RJ, Ernstoff RM, Kaminski HJ, Keesey JC, Penn AS, et al. Myasthenia gravis: recommendations for clinical research standards. Task Force of the Medical Scientific Advisory Board of the Myasthenia Gravis Foundation of America. Ann Thorac Surg. 2000;70:327-34.

15. Osserman KE. Myasthenia gravis. New York: Grune \& Stratton; 1958:80-1.

16. Barohn RJ. Standards of measurements in myasthenia gravis. Ann N Y Acad Sci. 2003;998:432-9.

17. Sonnet JR, Jaretzki A III. Thymectomy for nonthymomatous myasthenia gravis. A critical review. Ann NY Acad Sci. 2008;1132:315-28.

18. Ware JE, Snow KK, Kosinski M. SF-36® Health Survey. Manual and Interpretation Guide. Lincoln, RI: Quality Metric Incorporated; 1993.

19. Okumura M, Inoue M, Kadota Y, Hayashi A, Tokunaga T, Kusu T, et al. Biological implications of thymectomy for myasthenia gravis. Surg Today. 2010;40: 102-7.

20. Zuckerman NS, Howard WA, Bismuth J, Gibson K, Edelman H, Berrih-Aknin S, et al. Ectopic germinal centers in the thymus of myasthenia gravis patients show characteristics of normal germinal centers. Eur J Immunol. 2010;40:1150-61.

21. Jaretzki A III. Thymectomy for myasthenia gravis. Analysis of the controversies regarding techniques and results. Neurology. 1997;48(Suppl 5):S52-63.

22. Strobl P, Moritz R, Leite MI, Willcox N, Chuang WY, Gold R, et al. The ageing and myasthenic thymus: a morphometric study validating a standard procedure in the histological workup of thymic specimens. J Neuroimmunol. 2008;201-2: 64-73.

23. Paul RH, Nash JM, Cohen RA, Gilchrist JM, Goldstein JM. Quality of life and well-being of patients with myasthenia gravis. Muscle Nerve. 2001;24:512-6. 